\title{
Pemanfaatan Persebaran Lokasi Jupiter Sebagai Media $E$ - Commerce Menggunakan Model Bisnis C2C
}

\author{
Jose Augusto Duarte Guterres ${ }^{1}$, Vera Selviana Adoe ${ }^{2}$ \\ STIKOM Artha Buana Kupang \\ e-mail: 1agoesttiles@gmail.com, ${ }^{2}$ veraanwar08@gmail.com \\ Diajukan: 30 April 2020; Direvisi: 21 Oktober 2020; Diterima: 27 Oktober 2020
}

\begin{abstract}
Abstrak
Penjualan merupakan kegiatan transactional yang dilakukan oleh para pelaku bisnis baik secara konvensional maupun secara elektronik. Saat ini, penjualan yang paling mudah dilakukan adalah penjualan secara elektronik dikarenakan sistem penjualannya tidak membutuhkan biaya yang mahal, cukup dengan media elektronik saja maka produk yang dijual dapat dilihat secara langsung oleh pembeli. Penjualan secara elektronik yang banyak dikenal yaitu e-commerce di mana tujuan dari e-commerce memberikan kemudahan bagi konsumen untuk dapat mengetahui secara pasti tersedia atau tidaknya suatu produk. Kendala utama masyarakat di Provinsi Nusa Tenggara Timur khususnya masyarakat kota dan Kabupaten Kupang dalam melakukan penjualan ternak yaitu waktu, lokasi, dan jarak tempuh. Selain itu, masyarakat sebagai pembeli juga masih sering mengalami kendala dalam membeli ternak dikarenakan, tidak semua ternak dapat ditemukan di pasar tradisional. Dikarenakan adanya permasalahan yang menjadi kendala masyarakat maka, peneliti ingin menawarkan Aplikasi Jupiter menggunakan sebuah konsep marketplace untuk mempertemukan antara penjual dan pembeli dengan model bisnis customer to customer (C2C) serta memanfaatkan Google Maps sebagai media navigasi. Peneliti menggunakan model pengembangan sistem yaitu V-Model dalam pengumpulan data hingga perancangan sistemnya. Dengan hasil yaitu aplikasi ini dapat memberikan kemudahan bagi penjual dalam memasarkan ternak dan pembeli dalam mencari dan menemukan titik lokasi penjualan ternak.
\end{abstract}

Kata kunci: Ternak, Marketplace, E-Commerce, C2C.

\begin{abstract}
Sales are transactional activities carried out by business people both conventionally and electronically. At present, the easiest selling is to sell electronically because the sales system does not require expensive costs, just enough with electronic media so the products sold can be seen directly by the buyer. Electronic sales are widely known, namely e-commerce where the purpose of e-commerce makes it easy for consumers to know for certain whether a product is available. The main obstacle for the people in the Province of East Nusa Tenggara, especially the people of the city and Regency of Kupang in selling livestock, is the time, location and distance traveled. In addition, the community as buyers also often experience obstacles in buying livestock because, not all livestock can be found in traditional markets. Due to the problems that have become community constraints, the researcher wants to offer the Jupiter Application using a marketplace concept to bring together sellers and buyers with a customer to customer $(C 2 C)$ business model and to use google maps as a navigation medium. Researchers used the V-Model system development model in collecting data and designing the system. With the results, this application offered could make it easier for sellers in marketing livestock and buyers to find and finding livestock sales locations.
\end{abstract}

Keywords: Cattle, Marketplace, E-Commerce, C2C.

\section{Pendahuluan}

Penjualan merupakan aktivitas menjual barang dagang yang menjadi usaha pokok suatu perusahaan dengan dilakukan secara terus menerus dan tepat [1] baik itu produk lokal, produk dalam negeri, maupun produk luar negeri. Demi melancarkan produk penjualan, saat ini banyak pelaku bisnis menggunakan fasilitas teknologi informasi guna memperlancar produk-produk yang ingin di pasarkan (diperjualbelikan), teknologi tersebut biasa dikenal dengan teknologi e-commerce (electronical commerce) [2]. E-commerce berfungsi untuk menghubungkan perusahaan atau perorangan sebagai konsumen dalam 
melakukan transaksi elektronik yang mencakup proses pemasaran, penjualan, pengiriman, pelayanan, dan pembayaran untuk berbagai produk dan jasa [3][4][5].

Dalam sistem e-commerce dikenal dengan 6 model bisnis yaitu business to business (B2B), business to customer (B2C), customer to customer $(\mathrm{C} 2 \mathrm{C})$, customer to business $(\mathrm{C} 2 \mathrm{~B})$, non business ecommerce, dan intrabusiness (organizational) e-commerce [6]. Model Bisnis C2C memiliki peran sebagai sebuah komunitas maupun wadah untuk menjalankan fungsi sosial dan fungsi bisnis dengan baik, sehingga pelaku bisnis mempunyai ketertarikan yang sama dalam bertukar informasi bahkan melakukan perdagangan [7]. Dengan adanya e-commerce maka teknologi smartphone juga dapat dikatakan sebagai salah satu media yang memiliki peran penting dalam membantu tercapainya sistem e-commerce. Smartphone dapat digunakan sebagai salah satu media digital marketing yang memudahkan promosi penjualan, dikarenakan dapat menjangkau semua kalangan, kapan pun, dengan cara apa pun, dan di mana pun [8] baik di kota/kabupaten maupun di desa.

Kabupaten Kupang merupakan salah satu kabupaten yang berada di dalam wilayah Indonesia Provinsi Nusa Tenggara Timur dengan jumlah penduduk yaitu sebanyak 372.777 jiwa serta memiliki 25 kecamatan yang tersebar mengelilingi Kota Kupang. Di Kabupaten Kupang aktivitas masyarakat sehariharinya selain bekerja sebagai Aparatur Sipil Negara (ASN), pegawai swasta, serta bertani (berkebun). Salah satu aktivitas masyarakat Kabupaten Kupang lainnya yaitu melakukan pemeliharaan dan penjualan ternak dengan jumlah populasi ternak yang bervariasi di seluruh wilayah kecamatan yaitu untuk ternak sapi sebanyak 586,717 ekor, ternak babi 404,837 ekor, ternak kerbau 2,036 ekor, ternak kuda 4,612 ekor, kambing 137,152 ekor, dan ternak domba sebanyak 176 ekor [9].

Permasalahan yang ada saat ini yaitu banyak pencari (pembeli) ternak selalu memiliki pertanyaan yaitu di manakah lokasi ternak yang ada? Selain masyarakat sebagai pembeli ada juga istilah masyarakat penjual (penjual ternak) dan mereka pun pastinya ingin menjual ternak mereka dengan cepat tanpa harus menggunakan cara lama yaitu harus berdagang di pasaran secara tradisional. Selain permasalahan di atas ada juga permasalahan yang lain seperti konsumen yang ingin mencari ternak untuk berkurban maupun yang ingin mengadakan suatu acara tertentu yang membutuhkan ternak, di saat seperti itu kadang masyarakat di kabupaten ataupun Kota Kupang mengalami kesulitan dalam mencari dan menemukan ternak dengan cepat serta harga yang lebih terjangkau.

Dikarenakan saat ini sistem tradisional sudah mengalami perubahan jaman oleh pengaruh teknologi maka peneliti ingin menawarkan sebuah produk transactional dengan mengadopsi sistem $e$ commerce dengan menerapkan model $\mathrm{C} 2 \mathrm{C}$ yang memberikan kebebasan bagi penggunanya untuk menyebarkan informasi kepada penjual maupun pembeli [10],[11]. Model C2C yang digunakan peneliti yaitu menggunakan konsep marketplace, di mana tujuan marketplace berfungsi sebagai sebuah media online perantara untuk memfasilitasi dan memberikan kemudahan informasi mengenai produk atau jasa yang ditawarkan, transaksi, maupun cara pembayaran [12][13][14], serta memanfaatkan layanan Google Maps sebagai petunjuk arah lokasi/navigasi penjualan ternak dari 1 titik tertentu ke titik yang lain (titik tujuan) [15]. Dengan menerapkan sistem tersebut maka hasil yang diharapkan agar masyarakat baik sebagai pelaku bisnis (pembeli dan penjual) bisa mendapatkan manfaat yang baik seperti kemudahan mendapatkan informasi mengenai lokasi-lokasi ternak hingga mengetahui contact person peternak sebagai media informasi kelanjutan dalam melakukan transaksi.

\section{Metode Penelitian}

\subsection{Metode Pengembangan Sistem}

V-Model merupakan salah satu model SDLC yang dikembangkan dari model Waterfall dan memiliki tahapan-tahapan yang hampir sama dengan Waterfall, hanya saja pada model ini tahapan pengujian dirinci untuk masing-masing tahapan [16]. V-Model pertama kali diusulkan oleh Paul Rook pada tahun 1980 dan dikenal dengan nama V-Model Tradisional [17]. Proses pengembangan sistem meliputi Requirement Analysis, Specification, Architectural Design, dan Detail Design. Sedangkan dalam proses pengujian meliputi Acceptance Testing, System Testing, Integration Testing, dan Units Testing. Di antara Develompment Activities dan Testing Activities terdapat proses penulisan kode [18]. Alur tahapan pada VModel dapat dilihat pada Gambar 1. 


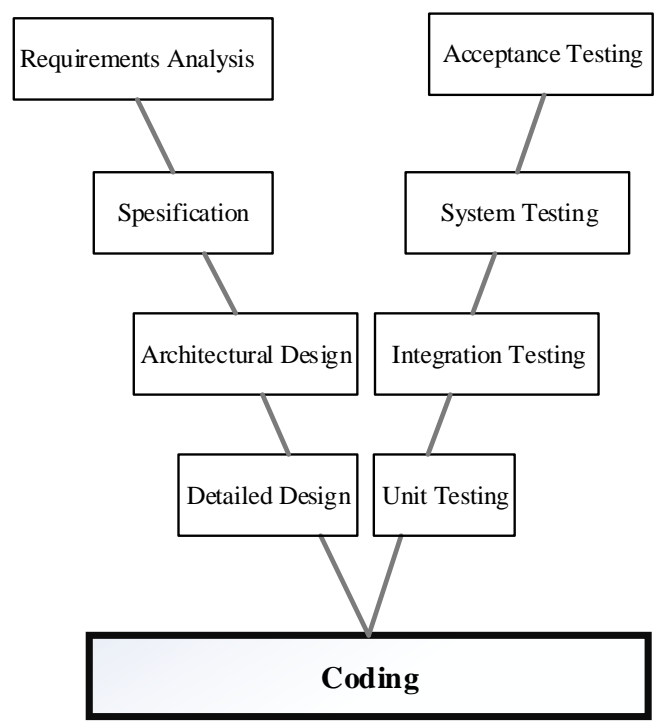

Gambar 1. Metode pengembangan sistem V-Model.

\subsection{Analisis Data dan Prosedur Pengumpulan Data}

Poin pada bagian ini, peneliti merujuk pada metode pengembangan system V-Model (Gambar 1) khususnya pada tahapan Requirements Analysis dan Spesification.

\subsubsection{Analisis Kebutuhan System}

Pada tahap ini, peneliti menganalisis untuk kebutuhan system melalui hasil observasi dan wawancara yang telah dilakukan pada pelaku bisnis (penjual dan pembeli ternak) di daerah Amarasi Barat, Amarasi Timur, Baubau, Oeba, Alak, serta para peternak yang ada di Kota Kupang dan Kabupaten Kupang.

\subsubsection{Prosedur Pengumpulan Data}

1. Observasi

Pada bagian ini, peneliti terjun langsung untuk melihat dan mengamati bagaimana transaksi penjualan dan pembelian yang dilakukan oleh pelaku bisnis, baik itu sebagai penjual ternak maupun pembeli ternak. Selain di pasar tradisional, peneliti juga melakukan observasi langsung di lokasi peternakan yang ada di daerah Amarasi Barat, Amarasi Timur, Baubau, Oeba, dan Alak. Hasil dari observasi menunjukkan bahwa proses penjualan dan pembelian ternak, selain harus menempuh jarak yang jauh, biaya dan waktu yang dibutuhkan khususnya penjual ternak cukup menguras tenaga dalam proses penjualan ternak.

\section{Wawancara}

Pada bagian ini, peneliti bertanya secara langsung kepada penjual ternak berupa waktu yang dibutuhkan untuk menempuh titik lokasi penjualan ternak (pasar tradisional) serta biaya perjalanan untuk penjualan ternak.

\section{Studi kepustakaan}

Pada bagian ini, peneliti menggunakan study kepustakaan berupa jurnal-jurnal yang relevan dengan tujuan penelitian peneliti, serta referensi-referensi lain seperti buku-buku maupun dokumen hasil observasi dan wawancara, sebagai bahan untuk menganalisis kebutuhan keseluruhan system. 


\subsection{Activity Diagram}

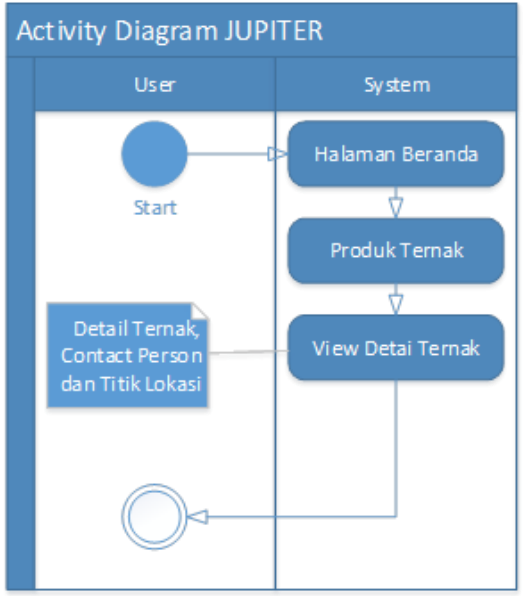

Gambar 2. Activity diagram perancangan Aplikasi Jupiter.

Pada Gambar 2 merupakan diagram activity dari aplikasi Jupiter di mana, saat user mengaktifkan aplikasi maka sistem akan menampilkan halaman beranda yang di dalamnya terdapat kategori Ternak, Peta Persebaran Ternak, serta Produk Terbaru. Selain itu, user juga dapat melihat detail ternak yang berisi contact person maupun titik lokasi penjualan ternak (merujuk pada Gambar 1, metode pengembangan system V-Model, tahapan Architectural Design dan Detailed Design).

\subsection{Use Case}

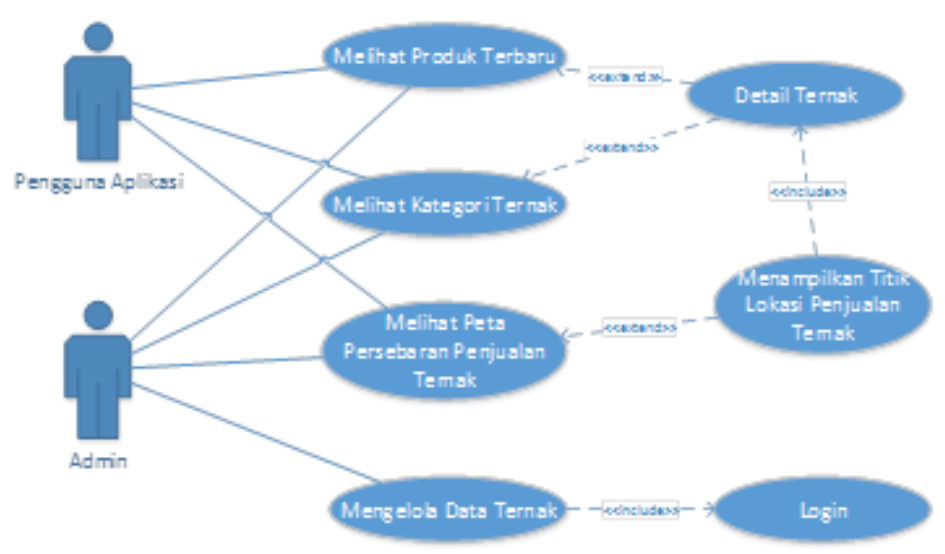

Gambar 3. Use case diagram.

Perancangan pada Gambar 3 menjelaskan tentang aktivitas-aktivitas yang dapat dilakukan oleh pengguna dan pengelola Aplikasi Jupiter. Dalam aplikasi tersebut terdapat 5 use case aktivitas yang dapat dilakukan oleh pengguna aplikasi, sedangkan pengelola aplikasi (admin) dapat melakukan 9 aktivitas pada use case (merujuk pada Gambar 1, metode pengembangan system, tahapan Architectural Design dan Detailed Design).

\section{Hasil dan Pembahasan}

Untuk hasil dan pembahasan, peneliti merujuk pada Gambar 1, metode pengembangan system, tahapan Coding, Unit Testing dan Integration System. Pada bagian Coding, peneliti menggunakan bahasa pemrograman Java dan PHP. Untuk unit testing, peneliti menguji coba hasil dari bahasa pemrograman dapat berjalan dengan baik ataupun tidak pada setiap bagian program yang sedang dikerjakan. Sedangkan pada bagian Intergration System, peneliti menghubungkan setiap bagian hasil coding dengan database, PHP dan Java, serta host domain. Hasil dari tahapan Coding, Unit Testing, dan Integration System dapat dilihat pada pembahasan di bawah ini (poin $3.1-3.6$ ): 


\subsection{Tampilan Awal}

Tampilan pada Gambar 4 merupakan tampilan awal dari aplikasi Jupiter. Di dalam tampilan awal terdapat beberapa bagian yang dipadukan menjadi satu (1) tampilan yaitu Halaman Gambar, Halaman Kategori, dan Halaman Produk Terbaru. Pada Halaman Gambar berisi gambar-gambar penjualan ternak, pada Halaman Kategori terdapat sub kategori jenis-jenis ternak, sedangkan pada Halaman Produk Terbaru merupakan data terbaru dari penjualan ternak.
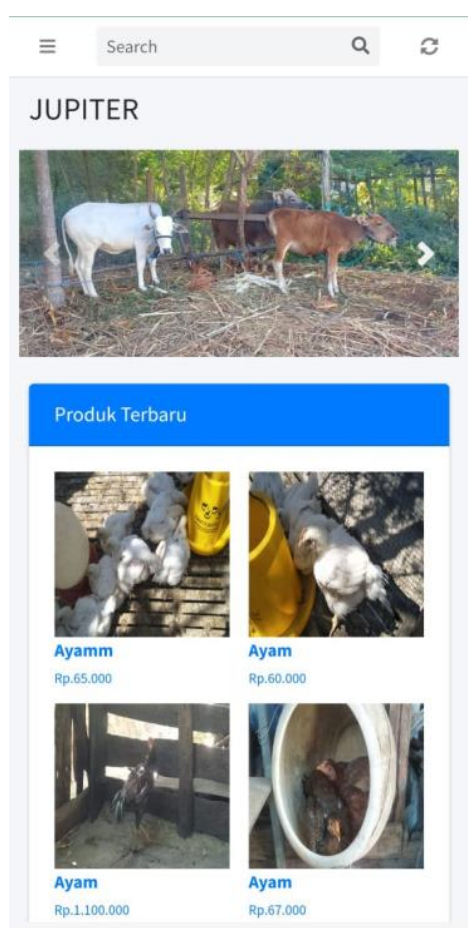

Gambar 4. Tampilan awal aplikasi Jupiter.

\subsection{Tampilan Kategori}

Tampilan Halaman Kategori seperti pada Gambar 5, akan ditampilkan jika pengguna aplikasi memilih salah satu kategori yang ada pada tampilan awal di Gambar 2. Di dalam Halaman Kategori terdapat sub kategori, yang berisi data-data yang sesuai dengan kategori yang dipilih. Pada Gambar 5 ini juga, pengguna aplikasi Jupiter dapat melihat gambar riil dari ternak yang akan dijual, harga serta harga dari tenak.

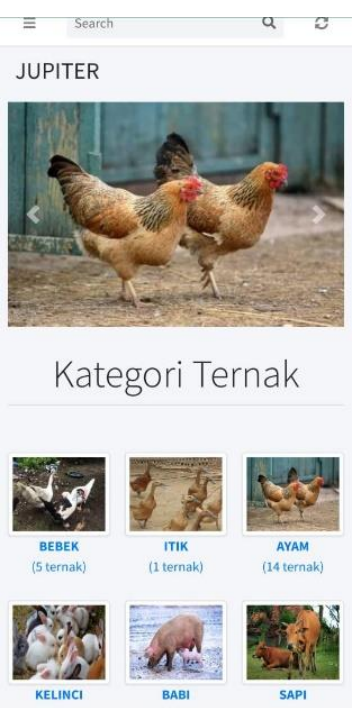

Gambar 5. Tampilan kategori ternak. 


\subsection{Tampilan Spesifikasi Ternak}

Tampilan Halaman Spesifikasi Ternak pada Gambar 6 berisi data detail dari ternak yang terdiri dari nama penjual ternak, harga ternak, contact person, serta peta lokasi penjualan ternak. Untuk melihat data contact person dan lokasi penjualan ternak pada peta dapat dilihat pada Gambar 7 dan Gambar 8 .

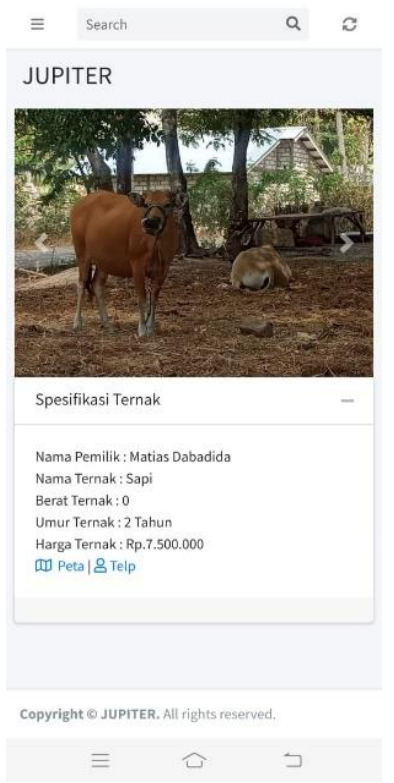

Gambar 6. Tampilan detail ternak.

\subsection{Tampilan Titik Lokasi dan Rute}

Pada Gambar 7 merupakan tampilan titik lokasi penjual ternak. Tampilan ini akan dihubungkan dengan Google Maps pada aplikasi Android. Di dalam tampilan ini, Google Maps dapat memberikan rute/jalur untuk menuju tempat lokasi penjual ternak.

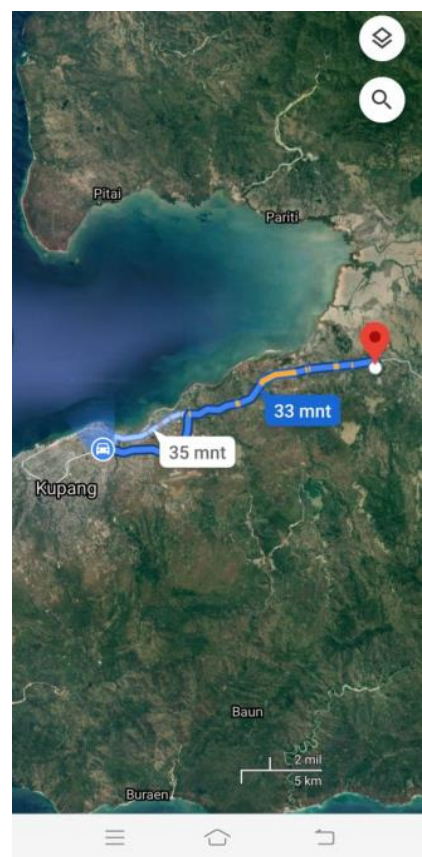

Gambar 7. Tampilan titik lokasi dan rute penjual ternak. 


\subsection{Tampilan Contact Person}

Tampilan pada Gambar 8 merupakan tampilan contact person yang dapat dihubungi oleh pembeli kepada penjual ternak. Fungsi dari tampilan ini yaitu agar memberikan kemudahan bagi pembeli, jika ingin mengetahui lebih jauh tentang ternak yang dijual oleh penjual.

Buat kontak baru

Tambahkan ke kontak yang ada

08123829155

$\begin{array}{lll}1 & 2 & 3 \\ 4 & 5 & 6 \\ 7 & 8 & 9 \\ \star & 0 & \# \\ \Omega & 4 & \end{array}$

Gambar 8. Tampilan contact person.

\subsection{Tampilan Persebaran Titik Lokasi Jupiter}

Tampilan pada Gambar 9 merupakan tampilan persebaran titik-titik lokasi pada aplikasi Jupiter. Fungsi dari tampilan ini, selain memberikan informasi persebaran lokasi penjualan ternak, persebaran ini pun memberikan kemudahan bagi pembeli jika ingin melihat titik lokasi penjualan ternak yang berada di sekitarnya. Di dalam persebaran titik lokasi Jupiter, jika pengguna titik lokasinya di pilih, maka system akan memberikan informasi tentang ternak, selain itu, jika customer selaku pembeli ingin melihat detail informasinya, system akan menampilkan detail seperti pada Gambar 6.

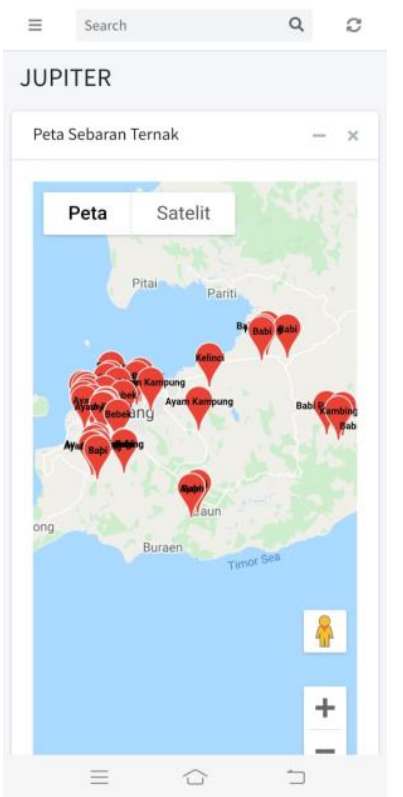

Gambar 9. Tampilan persebaran titik lokasi Jupiter.

\subsection{Pengujian Sistem}

Pengujian system dilakukan dengan dua (2) cara yaitu: 


\subsubsection{Pengujian Aplikasi}

Poin pada bagian ini, peneliti merujuk pada metode pengembangan system V-Model (Gambar 1) khususnya pada tahapan System Testing. Untuk pengujian aplikasi peneliti menggunakan pengujian black box (pengujian setiap komponen dalam aplikasi). Hasil pengujian adalah sebagai berikut:

1. Pengujian pada tampilan awal

a. Semua Sistem dapat berjalan dengan baik hanya pada slider tampilan gambar masih membutuhkan waktu \pm 10 detik dikarenakan masalah jaringan.

b. Pada produk terbaru, semua gambar dapat ditampilkan sesuai dengan data terbaru yang di-input.

c. Pada bagian drawer, sub-sub menu dapat di tampilkan dengan baik.

2. Tampilan pada menu Kategori

a. Semua sistem dapat berjalan dengan baik hanya pada slider tampilan gambar masih membutuhkan waktu \pm 30 detik dikarenakan masalah jaringan.

b. Tampilan kategori ternak dapat ditampilkan dengan baik.

3. Tampilan pada peta persebaran ternak

a. Tampilan pada peta persebaran titik lokasi penjualan ternak dapat berjalan dengan baik.

b. Detail pada peta persebaran juga dapat berjalan dengan baik.

4. Melihat tampilan detail ternak

a. Untuk melihat detail ternak maka, pengguna aplikasi harus memilih pada nama ternak, setelah di pilih nama ternak, maka system akan menampilkan detail ternak yang terdiri dari gambar ternak, spesifikasi ternak, telp, dan maps.

b. Jika memilih telp, maka system dapat menampilkan nomor kontak penjual ternak.

c. Jika memilih peta, maka system dapat menampilkan peta pada Google Maps, selain itu, Google Maps juga dapat menampilkan titik lokasi, jalur/rute dari penjual ternak.

5. Kesimpulan

Setalah melakukan pengujian menggunakan pengujian black box maka dapat disimpulkan bahwa aplikasi ini dapat dikatakan andal/berhasil.

\subsubsection{Pengujian Lapangan}

Poin pada bagian ini, peneliti merujuk pada metode pengembangan system V-Model (Gambar 1) khususnya pada tahapan Accepting Testing. Pada pengujian ini, merupakan pengujian yang dilakukan pada saat menguji keakuratan titik lokasi dan tanggapan masyarakat terhadap aplikasi. Hasil dari pengujian dapat dilihat pada Tabel 1 dan 2. Sedangkan untuk grafik pengujiannya dapat dilihat pada Gambar 10 dan 11.

Tabel 1. Pengujian dari segi penggunaan aplikasi.

\begin{tabular}{|c|c|c|c|c|c|c|}
\hline \multicolumn{2}{|r|}{ PERTANYAAN } & \multirow{2}{*}{$\begin{array}{c}\text { SS/SB } \\
43 \\
\end{array}$} & \multirow{2}{*}{$\begin{array}{c}\text { S/B } \\
7 \\
\end{array}$} & \multirow{2}{*}{$\begin{array}{c}\mathbf{C S} / \mathrm{CB} \\
0\end{array}$} & \multirow{2}{*}{$\begin{array}{c}\text { BS } \\
0 \\
\end{array}$} & \multirow{2}{*}{$\frac{\mathbf{K S} / \mathbf{K B}}{0}$} \\
\hline 1 & Bagaimana tanggapan Anda setelah menggunakan aplikasi Jupiter & & & & & \\
\hline 2 & $\begin{array}{l}\text { Setujukah Anda Aplikasi Jupiter dapat membatu masyarakat dalam } \\
\text { menjual dan membeli ternak? }\end{array}$ & 40 & 10 & 0 & 0 & 0 \\
\hline 3 & Setujukah Anda, Aplikasi ini lebih mudah dalam menjual ternak? & 48 & 2 & 0 & 0 & 0 \\
\hline & TOTAL & 131 & 19 & $\mathbf{0}$ & $\mathbf{0}$ & $\mathbf{0}$ \\
\hline & RATA2 dalam Persen(\%) & $\mathbf{8 7 , 3 3}$ & 12,67 & $\mathbf{0}$ & $\mathbf{0}$ & $\mathbf{0}$ \\
\hline
\end{tabular}

Ket. SS/ SB= Sangat Setuju /Sangat Bagus; S/B = Setuju/Bagus; CS/CB =Cukup Setuju/Cukup Bagus; BS = Biasa Saja; KS/KB = Kurang Setuju/Kurang Bagus.

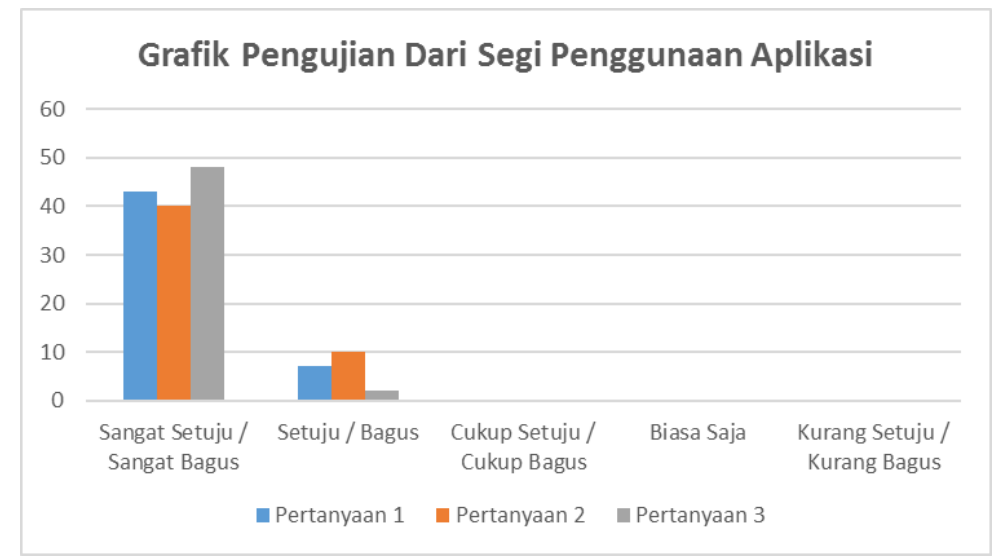

Gambar 10. Grafik pengujian dari segi penggunaan aplikasi.

Pemanfaatan Persebaran Lokasi Jupiter Sebagai Media E-commerce Menggunakan Model Bisnis C2C (Jose Augusto Duarte Guterres) 
Tabel 2. Pengujian dari segi keakuratan titik lokasi.

\begin{tabular}{|c|c|c|c|c|c|c|}
\hline \multicolumn{2}{|r|}{ PERTANYAAN } & \multirow{2}{*}{$\begin{array}{c}\text { SS/SB } \\
20\end{array}$} & \multirow{2}{*}{$\begin{array}{c}\mathbf{S} / \mathbf{B} \\
0\end{array}$} & \multirow{2}{*}{$\frac{\mathrm{CS} / \mathrm{CB}}{0}$} & \multirow{2}{*}{$\begin{array}{c}\text { BS } \\
0\end{array}$} & \multirow{2}{*}{$\begin{array}{c}\mathbf{K S} / \mathbf{K B} \\
0\end{array}$} \\
\hline 1 & $\begin{array}{l}\text { Setujukah Anda bahwa aplikasi ini dapat menampilkan titik lokasi } \\
\text { penjualan ternak? }\end{array}$ & & & & & \\
\hline 2 & $\begin{array}{l}\text { Setujukah Anda bahwa aplikasi ini dapat menampilkan rute/jalur } \\
\text { lokasi penjualan ternak? }\end{array}$ & 19 & 1 & 0 & 0 & 0 \\
\hline 3 & $\begin{array}{l}\text { Setujukah Anda, rute jalur lokasi penjualan ternak melewati jalur- } \\
\text { jalur utama jalan raya? }\end{array}$ & 14 & 4 & 2 & 0 & 0 \\
\hline 4 & $\begin{array}{l}\text { Setujukah Anda aplikasi ini dapat memberikan keakuratan titik lokasi } \\
\text { penjualan ternak? }\end{array}$ & 19 & 1 & 0 & 0 & 0 \\
\hline 5. & $\begin{array}{l}\text { Bagaimana Pendapat Anda tentang waktu dan jarak tempuh menuju } \\
\text { titik lokasi penjualan ternak, apakah Anda setuju bahwa waktu dan } \\
\text { jarak tempuh yang di tampilkan pada Google Maps sesuai dengan } \\
\text { waktu riil? }\end{array}$ & 14 & 0 & 0 & 0 & 6 \\
\hline & \begin{tabular}{|c|} 
TOTAL \\
\end{tabular} & 86 & 6 & 2 & $\mathbf{0}$ & 6 \\
\hline & RATA2 dalam Persen(\%) & 86 & 6 & 2 & $\mathbf{0}$ & 6 \\
\hline
\end{tabular}

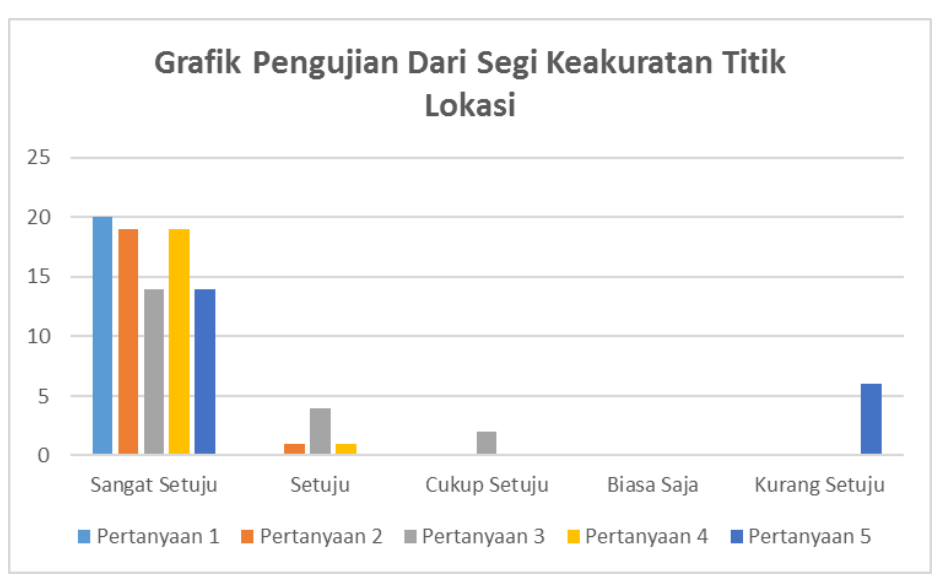

Gambar 11. Grafik pengujian dari segi keakuratan titik lokasi.

\section{Kesimpulan}

Berdasarkan hasil pengujian baik itu pengujian aplikasi maupun pengujian lapangan, serta tahapan-tahapan yang telah dilalui dari pengembangan system V-Model maka dapat disimpulkan bahwa Aplikasi Jupiter dapat dikatakan berhasil, dikarenakan:

a. Dapat memberikan kemudahan bagi penjual maupun pembeli ternak dalam mencari dan menemukan lokasi penjualan ternak.

b. Penjual selaku customer dapat dengan mudah memasarkan ternaknya tanpa harus menempuh jarak tempuh yang lebih jauh untuk menjual ternak.

c. Pembeli selaku customer juga dapat dengan mudah melihat kondisi ternak serta dengan mudah mengetahui ketersediaan ternak yang ingin di cari serta aplikasi Jupiter dapat memberikan rute/jalur dengan memanfaatkan Google Maps.

d. Dengan memanfaatkan smartphone Android maka penjual maupun pembeli (customer to customer/C2C) dapat dengan mudah bertransaksi serta bertukar informasi melalui layanan telepon yang telah tersedia pada aplikasi.

\section{Daftar Pustaka}

[1] A. Anthony, A. R. Tanaamah, A. F. Wijaya, F. T. Informasi, U. Kristen, and S. Wacana, "Analisis dan Perancangan Sistem Informasi Penjualan Berdasarkan Stock Gudang Berbasis Client Server," J. Teknol. Inf. dan Ilmu Komput., vol. 4, no. 2, pp. 136-147, 2017.

[2] H. Himawan, A. Saefullah, and S. Santoso, "Analisis dan Perancangan Sistem Informasi Penjualan Online (E-commerce) pada CV Selaras Batik Menggunakan Analisis Deskriptif," Sci. J. Informatics, vol. 1, no. 1, pp. 53-63, 2015, doi: 10.15294/sji.vli1.3641.

[3] Y. Yulianto, F. Alfiah, E. P. Harahap, and B. A. Pahad, "Analisis Peranan Teknologi Internet Sebagai Media Transaksi E-commerce Dalam Meningkatkan Perkembangan Ekonomi," Semin. Nas. Teknol. Inf. dan Multimed., pp. 25-29, 2015, [Online]. Available: https://ojs.amikom.ac.id/index.php/semnasteknomedia/article/view/827.

[4] S. Maryama, "Penerapan E-commerce Dalam Meningkatkan Daya Saing Usaha," Liquidity, vol. 2, 
no. 1, pp. 73-79, 2018, doi: 10.32546/lq.v2i1.132.

[5] R. Yustiani and R. Yunanto, "Peran Marketplace sebagai Alternatif Bisnis di Era Teknologi Informasi," J. Ilm. Komput. dan Inform., vol. 6, no. 2, pp. 43-48, 2017.

[6] Nuryanti, "Peran E-commerce Untuk Meningkatkan Daya Saing Usaha Kecil dan Menengah ( UKM )," J. Ekon. Manaj. Ekon. Univ. Riau, vol. 21, no. 4, p. 15, 2013, doi: 10.1073/pnas.0703993104.

[7] P. Hartiwi, Darman, and N. Enny, "Analisis Kepercayaan dalam C2C E-commerce terhadap Keputusan Pembelian dan Dampaknya terhadap Repurchase pada Kaskus," Binus Bus. Rev., vol. 5, no. 1, pp. 301-314, 2014, doi: 10.21512/bbr.v5i1.1218.

[8] F. Oktaviani and D. Rustandi, "Implementasi Digital Marketing dalam Membangun Brand Awareness," PRofesi humas J. Ilm. ilmu Hub. Masy., vol. 3, no. 1, p. 1, 2018, doi: 10.24198/prh.v3i1.15878.

[9] K. BPS Kabupaten, “Kupang Dalam Angka 2018,” 1102001.5303. BPS Kabupaten Kupang, p. 347, 2018.

[10] L. Agustina and F. Kurniawan, "Sistem Reputasi Penjual dalam Proses Pengambilan Keputusan Pembelian di Platform C2C E-commerce," J. Komun. Indones., vol. 7, no. 1, 2018, doi: 10.7454/jki.v7i1.9700.

[11] Y. Windarto, "Pengaruh Usability Factor Website E-commerce Model B2C Terhadap Kepercayaan User," J. Sist. Inf., vol. 8, no. 2, pp. 1106-1120, 2016.

[12] N. Kadek, Y. Utami, N. Made, and S. Wahyuni, "Kajian Usability E-Marketplace Bluprin Sebagai Direktori Bidang Arsitektur dan Desain Interior Dalam Dunia Digital," Senada, vol. 2, pp. 589597, 2019.

[13] M. Robert and T. P. N. Bernadheta, "Analisis Sistem Informasi E-Marketplace Pada Usaha Kecil Menengah (UKM) Kerajinan Bambu Dusun Brajan,” Data Manaj. dan Teknoligi Inf., vol. 18, no. 2, pp. 48-53, 2017.

[14] A. I Putu and P. Tubagus, "Efektifitas Marketplace dalam Meningkatkan Konsentrasi Pemasaran dan Penjualan Produk Bagi UMKM di Jawa Timur," ResearchGate, no. April, 2019, doi: 10.13140/RG.2.2.10157.95206.

[15] J. A. D. Guterres and M. M. Belalawe, "Pengembangan Appel Sarada Dengan Memanfaatkan Metode haversine Formula," Teknika, vol. 8, no. 1, pp. 68-73, 2019, doi: 0.34148/teknika.v8i1.146.

[16] R. Indah, Y. T. Mursityo, and M. C. Saputra, "Pengembangan Sistem Informasi Izin Kerja Dan Praktik Tenaga Kesehatan ( SINKES ) Dinas Kesehatan Kota XYZ,” J. Pengemb. Teknol. Inf. dan Ilmu Komput. Univ. Brawijaya, vol. 2, no. 12, pp. 6176-6185, 2018.

[17] D. I. Windi Eka Y.R, Saiful Bukhori, "Perbandingan V-Model Tradisional dan Advance V-Model," Pros. Semin. Nas. Ilmu Komput. 2013, no. November, pp. 49-53, 2013.

[18] S. Mathur and S. Malik, "Advancements in the V-Model," Int. J. Comput. Appl., vol. 1, no. 12, pp. 30-35, 2010, doi: 10.5120/266-425. 